\title{
Moving Opportunism to the Back Seat Bounded Rationality. Costly Conflict, and Hierarchical Forms
}

Foss, Nicolai Juul; Weber, Libby

Document Version

Final published version

Published in:

Academy of Management Review

DOI:

10.5465/amr.2014.0105

Publication date:

2016

License

Unspecified

Citation for published version (APA):

Foss, N. J., \& Weber, L. (2016). Moving Opportunism to the Back Seat: Bounded Rationality. Costly Conflict, and Hierarchical Forms. Academy of Management Review, 41(1), 61-79. https://doi.org/10.5465/amr.2014.0105

Link to publication in CBS Research Portal

\section{General rights}

Copyright and moral rights for the publications made accessible in the public portal are retained by the authors and/or other copyright owners and it is a condition of accessing publications that users recognise and abide by the legal requirements associated with these rights.

Take down policy

If you believe that this document breaches copyright please contact us (research.lib@cbs.dk) providing details, and we will remove access to the work immediately and investigate your claim. 


\title{
Moving Opportunism to the Back Seat: Bounded Rationality. Costly Conflict, and Hierarchical Forms
}

\section{Nicolai Juul Foss and Libby Weber}

\author{
Journal article (Final published version)
}

CITE: Moving Opportunism to the Back Seat : Bounded Rationality. Costly Conflict, and Hierarchical Forms. / Foss, Nicolai Juul; Weber, Libby. In: Academy of Management Review, Vol. 41, No. 1, 2016, p. 61-79.

DOI: $\underline{10.5465 / a m r .2014 .0105}$

Uploaded to Research@CBS: January २०1८ 


\title{
MOVING OPPORTUNISM TO THE BĀCK SEAT: BOUNDED RATIONALITY, COSTLY CONFLICT, AND HIERARCHICAL FORMS
}

\author{
NICOLAI J. FOSS \\ Copenhagen Business School and Norwegian School of Economics \\ LIBBY WEBER \\ University of California, Irvine
}

\begin{abstract}
We augment transaction cost economics' bounded rationality assumption with heuristics (framing) and cognitive biases to expand the understanding of hierarchical governance in the theory. In transaction cost economics opportunism traditionally takes the front seat, while bounded rationality is primarily relegated to the support role of invoking incomplete contracts. The theory also suggests that hierarchical governance effectively mitigates opportunism-based transaction costs, making it difficult to explain why hierarchies are not always used. However, when an augmented bounded rationality assumption is incorporated into transaction cost economics, we argue, first, that bounded rationality is a separate source of transaction costs and, second, that these costs are not equally mitigated by all forms of hierarchy. Instead, different hierarchical forms are associated with particular frames and social referents that naturally enhance specific bounded rationality-based conflicts, allowing certain hierarchical forms to mitigate bounded rationality-based transaction costs better than others. As a result, bounded rationality takes $\alpha$ front seat in the theory, addressing prior critiques of the theory, expanding the governance questions addressed by the theory, and creating a new moderating role for asset specificity in internal exchanges.
\end{abstract}

In transaction cost economics (TCE), contracting issues only arise when both bounded rationality and opportunism are present. Although both behavioral assumptions are considered essential in TCE, we suggest that the focus is primarily on mitigating opportunism-based transaction costs, while those that arise from bounded rationality are largely ignored. As a result, opportunism takes a front seat in the theory, with bounded rationality relegated to the explanatory backseat. We argue the imbalance occurs because the bounded rationality assumption is underdeveloped in TCE, focusing only on

We thank participants of the 2013 Academy of Management annual meeting, the 2013 Atlonta Competitive Advantage Conference, the 2013 Strategic Management Society Conference, and the 2014 INFORMS Conference in the Organization Science Track for their constructive comments that helped us develop the paper. Additionally, we thank participants of the Emory University Colloquia Series and the Syracuse University Colloquia Series and attendees at the internal seminars at Bocconi University, Saïd Business School, and University of California, Irvine for their insightful comments. We are especially grateful to our anonymous reviewers and former associate editor Cindy Devers for their guidance, which we feel improved the article significantly. We also particularly thank Phil Bromiley and Margarethe Wiersema for their feedback on the manuscript during its development. processing capacity limits, which lead to incomplete contracts (Foss, 2003). By augmenting the bounded rationality assumption with heuristics (specifically frames) and cognitive biases, we move bounded rationality to the front seat, allowing us to address a long-standing critique of hierarchy in $\mathrm{TCE}$, to extend the theory to choices between internal governance forms, and to uncover a new role for asset specificity in internal exchanges.

Critics have challenged that TCE does not adequately explain when hierorchies may fail (why all transactions are not organized in firms as opposed to other governance forms) and, therefore, the limits of hierarchy (e.g., Gibbons, 2010; Grossman \& Hart, 1986; Nickerson \& Zenger, 2008; Zenger, Lazzarini, \& Poppo, 2002). Instead, TCE scholars consider hierorchy to be an effective governance mechanism to mitigate opportunism-based transaction costs. Additionally, the theory considers all forms of hierarchy equally efficient at mitigating these costs, despite the fact there are mony different types of hierorchy. ${ }^{1}$

\footnotetext{
${ }^{1}$ The exception is the insight that the multidivisional form (M-form) more effectively mitigates managers' bounded rationality arising from "communication overload" (Williamson, 1985: 281).
} 
We argue that an underdeveloped bounded rationality assumption leads to this simplistic view of hierarchy, since bounded rationality-based transaction costs are not considered in governance decisions.

Although TCE has been augmented in various ways over the last decades (e.g., Bromiley \& Harris, 2006; Mayer \& Argyres, 2004; Nickerson \& Zenger, 2004; Weigelt \& Miller, 2013; Williamson, 2000), cognitive influences informed by advances in psychology and neuroscience have largely been ignored (for an exception see Weber \& Mayer, 2014), even though Simon (1997: 80) himself viewed systematic information distortions as part of bounded rationality. Augmenting TCE's bounded rationality assumption with heuristics (simplified models of reality, such as fromes, that help individuals and groups make sense of a complex world) and cognitive biases allows us to expand beyond its current ex ante function of explaining why contracts are incomplete to an important ex post role as a source of "maladaptation costs," a major focus in TCE (Williamson, 2000). The key idea is that frames and biases, which are linked to different hierarchal forms, may give rise to costly conflicts that are entirely rooted in bounded rationality, as opposed to opportunism. Specific hierarchical forms-notably, the unitary, multidivisional, and project matrix forms-exacerbate or attenuate such conflicts to different degrees, which implies that the choice of hierarchical form becomes important for minimizing bounded rationality-based transaction costs.

Augmenting the bounded rationality assumption moves it to the front seat in TCE, since it plays a much more substantial role in the theory. Note that we do not seek to eliminate opportunism from TCE. Instead, we argue that bounded rationality is an alternative source for significant transaction costs, even in the absence of opportunism. Thus, we argue that bounded rationality has a main effect on transaction costs, whereas opportunism only leads to transaction costs in the presence of bounded rationality. Relatedly, we argue that the traditional TCE transaction dimensions of uncertainty, frequency, and asset specificity may have different effects on bounded rationality-based transaction costs than on traditional opportunismcentric TCE.

In sum, we make three overall contributions to organizational theory in general and TCE specifically. First, we propose that transaction costs may be caused by bounded rationality-based conflict rather than blatant opportunism, since inherent intergroup conflict and unintentional misunderstandings can be just as costly. Second, we argue that different hierarchical forms facilitate specific cognitive frames and biases, linking them to particular bounded rationality-based conflicts. Third, we posit that some hierarchical forms mitigate bounded rationality-based transaction costs better than others.

\section{BOUNDED RATIONALITY IN TRADITIONAL TCE}

TCE rests on two behavioral assumptions: opportunism and bounded rationality (Williamson, 1985). Bounded rationality prevents parties from including all relevont contingencies in their contracts, while opportunism suggests that the exchange partner may take advantage of the incomplete contract. Without bounded rationality, market contracting can coordinate all economic activity and handle all problems of misaligned incentives, eliminating the need for discriminant analysis of different governance structures (the main interest of TCE; Williamson, 1996: 36).

Given its purported centrality in the theory, one may expect bounded rationality to be precisely defined in the TCE literature (cf. Suddaby, 2010). Williamson usually quotes Simon's statement that man is "intendedly rational, but limitedly so" (Simon, 1947: xxiv). However, this is not a precise definition but simply an acknowledgment that rationality is not maximized. ${ }^{2}$ We suggest that the vague definition results in a one-dimensional bounded rationality assumption in TCE that takes a back seat to opportunism. That is, once bounded rationality (defined as processing capacity limitations) makes contracts incomplete, it is no longer considered in the theory. Insteod, the focus in traditional TCE is primarily on mitigating opportunism-based transaction costs in the presence of incomplete contracts through efficient governance choice. Conversely, we argue that if TCE's bounded rationality assumption is expanded to include all components of bounded rationality (i.e., processing capacity limitations, cognitive economizing in the form of heuristics, and cognitive biases), it can play a much more central role in the theory.

\footnotetext{
${ }^{2}$ Williamson also refers to Simon's later work (e.g., Simon, 1957), noting that bounded rationality "involves neurophysiological limits on the one hand and language limits on the other" (Williamson, 1975: 21), but does not specify these limits.
} 


\section{Components of Bounded Rationality}

Bounded rationality is one of the few behavioral assumptions shared by most management scholars across a broad range of management research fields (March 1994; Mumby \& Putnom, 2002). It has three interrelated dimensions (Foss, 2003; Simon, 1997): (1) processing capacity (e.g., Simon, 1947), (2) cognitive economizing (e.g., Fiske \& Torylor, 199l; Simon, 1990), and (3) cognitive biases (e.g., Tversky \& Kahneman, 1974). These three aspects progressively build on each other to bound human rationality.

Processing capacity. First, the human copacity to interpret and process information is quite limited (Simon, 1990: 7). These bounds arise in the form of physical limitations on short-term working memory (e.g., Feather, 1999; Lisman \& Idiart, 1995) and attention (e.g., Shiffrin \& Schneider, 1977), which tronslate into "limited foresight, imprecise language, the costs of calculating solutions and the costs of writing down a plan" (Milgrom \& Roberts, 1992: 128). They make it impossible for the human brain to process all of the information that may be pertinent to a particular decision (Simon, 1947), restricting the quantity of information processed during a decision.

Cognitive economizing. Simon (1990: 6) argued that humans must use approximate methods to handle most tasks because of limits on their computing speed. As a result, humans act as cognitive misers (Fiske \& Taylor, 1991), relying on shortcuts called heuristics to organize a subset of the information, instead of systematically processing all of the available information (Gigerenzer, 2003). Heuristics, which include fromes (Gigerenzer, 2003) and stereotypes (Bodenhausen \& Wyer, 1985), are considered highly functional, allowing humans to make decisions in a complex world (Gigerenzer, Todd, \& ABC Research Group, 1999; Tversky \& Kahneman, 1974; Winkler \& Murphy, 1973).

Cognitive biases. Although heuristics generally assist decision making, they can also lead to large systematic errors in judgment (Tversky \& Kahneman, 1974). These cognitive biases unconsciously distort the information that is processed (Dutton \& Jackson, 1987), rather than impacting the amount of information processed. Examples include the fundormental attribution error (Jones \& Harris, 1967), self-serving bias (Heider, 1958), and confirmation bias (Wason, 1960).

\section{Augmenting the Traditional Bounded Rationality Assumption}

Over the last six decades, bounded rationality research has evolved from the introduction of satisficing (i.e., Simon, 1947) to the examination of heuristics (e.g., March \& Simon, 1958; Newell \& Simon, 1972) to the investigation of biases and errors arising from cognitive shortcuts (e.g., Pohl, 2004; Tversky \& Kahneman, 1974). This evolution was driven by advances in evolutionary psychology, social psychology, and neuropsychology (e.g., Cowan, 2000; Shiffrin \& Schneider, 1977) and by behavioral and experimental economics (e.g., Fox \& Tversky, 1995; Kahneman \& Tversky, 1979). Despite such advances in bounded rationality research, TCE's traditional bounded rationality assumption only incorporates processing capacity, the most basic of the three components (cf. also Mahoney \& McGahan, 2007).

Williamson was quite explicit about this choice, arguing that there are two forms of economizing on bounded rationality: heuristic problem solving and discriminant alignment of governance structures. Williamson's argument was that the former is not related to the central focus of TCE-assigning transactions to governance structures in a discriminating way (Williamson, 1985: 46). Thus, Williamson explicitly chose to omit heuristics and cognitive biases from the bounded rationality assumption in TCE because he felt they do not have a significant impact on governance choice.

Embracing this one-dimensional bounded rationality assumption has three main implications for the theory. First, it limits the role of bounded rationality in TCE to simply making complex contracts incomplete (Williamson, 2000), which fundamentally makes bounded rationality an auxiliary assumption. As a result, it is not fully integrated into the theory, suggesting that managers are otherwise sufficiently rational to implement efficient governance structures (Williamson, 1985). Additionally, transaction costs in TCE are primarily based on opportunism rather than bounded rationality. Holdup and shirking, clearly arising from opportunism in the face of incomplete contracts, are key drivers of governance decisions in TCE (Williamson, 1985), while information processing costs (the only bounded rationality-based transaction costs considered) play much less of a role (Williamson, 1985). Finally, the one-dimensional bounded rationality assumption results in an overly narrow understanding of hierarchy in TCE, since it is an implicit assumption that all forms of hierarchy are equally efficient at mitigating opportunism-based 
transaction costs, despite the fact that there are many different types of hierarchy to choose from when internalizing a transaction. ${ }^{3}$

Although TCE has been augmented in various ways over the last decades, including new "shift parameters" (e.g., institutions; Williamson, 2000), trust (Bromiley \& Harris, 2006), problem solving (Nickerson \& Zenger, 2004), learning (Mayer \& Argyres, 2004), knowledge flows (Weigelt \& Miller, 2013), and hybrid forms (Williamson, 1996), cognitive influences informed by advances in psychology and neuroscience have largely been ignored (Foss, 2003; for an exception see Weber \& Mayer, 2014). We argue that when cognitive economizing (heuristics) and cognitive biases (the two missing components) are incorporated into TCE's bounded rationality assumption, this can lead to transaction costs, even in the absence of opportunism (e.g., costs arising from different interpretations, as opposed to deliberate opportunism). Specifically, we argue that this addition expands the concept of hierarchy by addressing a long-standing critique in TCE, extending the theory's standard applications to internal governance choice, and uncovering a new role for asset specificity in internal exchanges.

\section{LINKING HIERARCHAL FORMS TO SPECIFIC FRAMES AND COGNITIVE BIASES}

Several research streams suggest that different organizational forms are systematically associated with specific cognitive factors. First, organizational theorists argue that firm structure and control (the concrete form that governance takes) determine where boundedly rational organizational members allocate their scarce attention (March \& Simon, 1958). Ocasio (1997) expands this idea, proposing an attention-based theory of the firm. Additionally, Nickerson and Zenger (2004) argue that different hierarchical forms are systematically associated with specific problem-solving

\footnotetext{
${ }^{3}$ The one exception to this issue is when Williamson discusses the change from the U- to the M-form (Chandler, 1962). Here he points out that "bounds of rationality were reached as the U-form structure labored under a communication overload while the pursuit of subgoals by the functional parts ... was partly a manifestation of opportunism" (Williamson, 1985: 280-281). In contrast, the M-form organization allows for better monitoring of subunits, moves more operational control to these units, and permits the corporate headquarters to concentrate on long-run strategic issues.
}

heuristics and therefore vary in how well they address different types of problems. ${ }^{4}$

We argue that this logic con be extended to different hierarchal structures. While traditional TCE often focuses on "simple hierorchy" (i.e., hierorchies with merely a single supervisor/manager; Williamson, 1975), this hierorchical form is only a temporary state for most firms, since they quickly grow too lorge to be managed by a single person. As such, we examine the link between more complex forms of hierorchy - the unitary form (orgonized by function), the multidivisional form (orgonized by products), and the project matrix form (a hybrid of both function and project)—and cognitive elements. ${ }^{5}$ Exponding on the prior link between organizational forms and cognitive elements and taking into account an expanded bounded rationality assumption, we focus on linking different hierorchal forms to particulor fromes (one of many potential heuristics) and cognitive biases.

\section{Fromes}

Cognitive fromes are heuristics (Gigerenzer, 2003) that allow humans with limited processing capacity to make sense of their complex world (Bateson, 1972; Goffman, 1974). Frames act as lenses that restrict the information set for a decision by directing attention to specific items and away from others (Entman, 1993). While fromes are ultimately held by individuals (Goffmon, 1974), organizational structure can act as a frome because its "characteristics organize a vast array of stimuli in the work setting to delimit a situation" (Herman, Dunham, \& Hulin, 1975: 231), leading to shared interpretations at the group or organizational level (e.g., Isenberg, 1986; Kaplon, 2008).

Variations in key organizational characteristics (e.g., physical segregation, group membership, incentives, and information flow) systematically guide how members interpret information (Whitford, 2006). Additionally, variation in other structural elements (e.g., career paths/mobility and socialization)

\footnotetext{
${ }^{4}$ In other work Nickerson and Zenger (2008) illustrate the impact that social comparison, a boundedly rational cognitive process, has on the boundaries of the firm. They argue that envy leads to social comparison costs, which are better mitigated outside the boundaries of the firm. As such, Nickerson and Zenger support the view that bounded rationality can impact governance choice.

${ }^{5}$ Although other hierarchal forms exist, these particular hierarchical forms represent a natural starting point to expand our understanding of hierarchy in TCE, because so many organizational theorists take them as organizational ideal types.
} 
influences the strength of these frames. See Table 1 for a summary of structural differences across the U-form, M-form, and project matrix.

Moreover, different organizational forms shape members' prior experiences and/or identification with specific frome elements, making some frames more salient (stronger) than others. Since stronger frames have a more significant impact on cognition (Benford \& Snow, 2000), organizational form also influences the extent to which different frames impact members' cognition. As a result, different hierarchal structures promote specific frames and directly influence their salience levels.

\section{Cognitive Biases}

Cognitive biases are systematic errors that arise from the use of heuristics, such as frames (Tversky \& Kahneman, 1974). Although there are many different cognitive biases, social comparison biases are particularly important in the context of hierarchy (Nickerson \& Zenger, 2008). These biases can arise at the individual level (superiority bias, egocentric bias, and self-serving bias) or group level (ingroup bias), depending on whether the organizational structure invokes the employee's individual or group identity (Brewer \& Gardner, 1996).

Similar to frames, differences in organizational structure impact activation of a group or individual identity. The stability of group membership and the identity and salience of referents directly impact which social comparisons organizational members make and their related biases. See Table 2 for a summary of the drivers of specific identity levels across different hierorchal forms.

When hierarchical forms highlight individuals' differences through interpersonal competition, individual incentives, and transient group memberships, an individual identity (a self-conception composed of the individual's personal characteristics as compared to others' personal characteristics; Brewer \& Gardner, 1996) is activated (Brickson, 2000). Under this identity, individuals tend to compare themselves to other individuals (Brewer \& Gardner, 1996), leading to individuallevel social comparison biases. In contrast, a group identity (a more inclusive self-conception based on similarities to others; Brewer \& Gardner, 1996) is activated when group membership is emphasized and group performance is incentivized (Brickson, 2000). As a result, employees compare members of their group to members of other groups (Brewer \& Gardner, 1996), leading to group-level social comparison biases. Thus, specific hierarchical forms are associated with particular social comparison biases.

To understand how different frames and cognitive biases emerge in different hierarchical forms, we must examine their structural characteristics, including physical segregation, group membership, incentives, information flow, career paths/mobility, socialization, and referent groups. These structural characteristics shape employees' attention (Ocasio, 1997), activating particular frames and levels of social identity (individual or group) that lead to specific social comparison biases (Brewer \& Gardner, 1996). Based on this analysis, our first set of propositions links different types of bounded rationality-based

TABLE 1

Underlying Drivers of Specific Frames in Different Hierarchical Forms

\begin{tabular}{|c|c|c|c|}
\hline Drivers & Unitary & Multidivisional & Project Matrix \\
\hline $\begin{array}{l}\text { Physical } \\
\text { segregation }\end{array}$ & By function & By product division & None or by project \\
\hline $\begin{array}{l}\text { Group } \\
\text { membership }\end{array}$ & Functional & Product division & Project \\
\hline Incentives & Functional level & Business unit level & Individual level \\
\hline Information flow & Functional silos (insular) & Business unit silos (less insular) & Between project groups \\
\hline Socialization & $\begin{array}{l}\text { Starts with formal education; } \\
\text { continues in functional area }\end{array}$ & $\begin{array}{l}\text { Within business unit, but } \\
\text { weaker indoctrination }\end{array}$ & $\begin{array}{l}\text { Individual level; adept at integrating } \\
\text { different views }\end{array}$ \\
\hline Career path & Careers within a single function & $\begin{array}{l}\text { Business unit-specific careers } \\
\text { cutting across functional areas }\end{array}$ & Career path for individual specialist \\
\hline Mobility & Low & Medium & High \\
\hline Frame & Functional & Divisional & Individual \\
\hline
\end{tabular}


TABLE 2

Underlying Drivers of Social Comparison Biases in Different Hierarchical Forms

\begin{tabular}{llll}
\hline Drivers & Unitary & Multidivisional & Project Matrix \\
\hline Identity-level activation & Group & Group & Individual \\
Group membership stability & Permanent & Semi-permanent & Temporary \\
Referent groups & Other functional areas & Other divisions & Other individuals \\
Referent group salience & Strong & Weaker & Strong \\
Bias level & Intergroup & Intergroup & Interpersonal \\
\hline
\end{tabular}

conflict to different hierarchal forms as a result of frame misalignment and social comparison biases: (1) interpretation-based conflict stemming from nonoverlapping incompatible frames, (2) evaluation-based conflict arising from social comparison biases at different levels, and (3) rolebased conflict arising from nonoverlapping compatible frames and a highly salient social referent. Although this list is not exhaustive, it captures important sources of bounded rationality-based conflicts in hierarchical exchanges. See Table 3 for an overview of the cognitive bases of these bounded rationality-based conflicts in each hierarchical form.

In our second set of propositions, we examine how the expanded bounded rationality assumption shifts asset specificity from its traditional role as a transaction hazard leading to opportunismbased transaction costs to a moderator of cognitive conflict levels in internal exchanges. Specifically, we suggest that increasing the level of unilateral asset specificity in internal transactions increases bounded rationality-based transaction costs. In contrast, we argue that increasing bilateral asset specificity decreases these same costs. These predictions concerning the impact of asset specificity extend the traditional prediction that high asset specificity leads to internalization of the transaction (Williamson, 1985).

Prior to presenting our propositions, we define boundary conditions for our theorizing. First, we address only transactions most efficiently governed by hierarchy - those characterized by high levels of asset specificity, frequency, and uncertainty (Williamson, 1985, 1996)—although we do address the consequences of variance even on the high end of the spectrum for asset specificity (in formal propositions) and uncertainty (in a brief discussion). Second, we have understandably not addressed all of the vast number of cognitive conflicts that may have on impact on hierarchical forms. Bounded rationality-based conflict includes any disagreement that arises from the use of heuristics or cognitive biases (Foss, 2003; Simon, 1997). Because of the plethora of heuristics and biases that people unconsciously use in the context of intraorganizational exchanges, the list of potential bounded rationality-based conflicts

TABLE 3

\section{Cognitive Bases of Conflict Across Hierarchical Forms}

\begin{tabular}{|c|c|c|c|}
\hline Conflict Type & Hierarchical Form & Bases & Likelihood \\
\hline \multirow[t]{3}{*}{ Interpretation } & Unitary & Nonoverlapping, incompatible functional frames & High \\
\hline & Multidivisional & $\begin{array}{l}\text { Nonoverlapping divisional frames with compatible functional frame } \\
\text { elements }\end{array}$ & Medium \\
\hline & Project matrix & Nonoverlapping individual frames with compatible elements & Low \\
\hline \multirow[t]{3}{*}{ Role } & Unitary & $\begin{array}{l}\text { Incompatible, nonoverlapping functional frames; high referent salience } \\
\text { and social projection }\end{array}$ & Low \\
\hline & Multidivisional & $\begin{array}{l}\text { Weaker divisional frames with compatible functional frame elements; } \\
\text { low referent salience and social projection }\end{array}$ & Medium \\
\hline & Project matrix & $\begin{array}{l}\text { Compatible elements of individual frames; high referent salience and } \\
\text { social projection }\end{array}$ & High \\
\hline \multirow[t]{3}{*}{ Evaluation } & Unitary & High outgroup salience, intergroup and group-serving biases & High \\
\hline & Multidivisional & Lower outgroup salience & Low \\
\hline & Project matrix & High outgroup salience, superiority, egocentric and self-serving biases & High \\
\hline
\end{tabular}


is extensive. Therefore, we focus on conflicts that have the most significant and direct bearing on the hierarchical form's ability to efficiently govern on internal transaction (i.e., those based on framing heuristics and social comparison biases). Finally, we focus on three hierarchal forms out of the many different possible organizational arrangements. The U-form and the M-form are natural choices for assessing the impact of an augmented bounded rationality assumption on hierarchy, as Williamson (1985) himself contrasted them in traditional TCE. Because we also wish to discuss a hierarchal form that blends characteristics of both the U-form (function based) and the M-form (product based), we focus on a matrix organization. Specifically, we chose to examine a project-based matrix because it is a hybrid form that crosses elements of both the U-form and M-form, which parallels Williamson's (1985) original governance continuum with two distinct end points and an intermediate hybrid form.

\section{Interpretation-Based Conflict}

Frames (e.g., Goffman, 1974; Kaplan, 2008) and the verbal codes that arise from them (Williamson, 1975) act as tools for interpreting information in exchanges. Both give meaning to expected and unexpected events in the exchange, rendering "what would otherwise be a meaningless aspect of a scene into something meaningful" (Goffman, 1974). When the actors in the exchange share both a dominant frame and similar verbal code (e.g., language or set of accepted acronyms), they develop a shared understanding of these events, as well as a common language with which to discuss it. However, when their frames and/or codes do not overlap or, even worse, are incompatible, there is great potential for a difference in interpretation, which will likely lead to interpretation-based conflict and, as a result, significant transaction costs in the exchange (Cronin \& Weingart, 2007; Weber \& Mayer, 2014). Structural differences across hierarchal forms lead to the emergence of specific types of frames with differing levels of compatibility, as well as variations in capabilities for negotiating a common frame between internal exchange parties.

U-form. A U-form hierarchy is organized along functional lines. For example, Netflix has six functional divisions: (1) marketing, (2) human resources, (3) operations, (4) finance, (5) product development, and (6) content development. The structural characteristics of a unitary hierarchy like Netflix lead to functional-level fromes (view of the world; see the "Unitary" column in Table 1). First, the physical segregation of employees into different functional groups focuses their attention on the tasks and goals required for that particular function (Ocasio, 1997). This segregation highlights membership within a specific functional group, leading to the development of shared frome elements through the process of depersonalization-the domination of group identity over individual identity (Turner, Hogg, Oakes, Reicher, \& Wetherell, 1987). Additionally, functional-level incentives in a U-form lead employees to focus on functional-level performance rather than their own individual performance (Ocasio, 1997). Again, this focus naturally influences the employees so that they view the world from their functional area's perspective rather than from an individual perspective. Finally, the information flow in a unitary hierarchy is largely siloed within each function, which prevents employees in one functional area from being exposed to different views of the exchonge (Bercovitz, Feldman, Feller, \& Burton, 2001). As a result, the functional specialists develop nonoverlopping, incompatible frames that are unique to their area, and they have no overlapping elements with the other functional areas (Weber \& Mayer, 2014).

Nonoverlapping, incompatible functional frames lead people in different functional areas to have very different interpretations of the same project (Schütz \& Bloch, 2006). Additionally, they often lead to different verbal codes, since the same word or acronym in one business unit can mean something entirely different in another unit. For example, in a biopharmaceutical company the acronym PC may mean "placebo control" in the R\&D division, "preclinical" in the regulatory division, "personal computer" in the IT division, and "politically correct" in the HR division (Evans, 2008: viii). As a result, when two functional areas engage in an internal exchange, conflict usually arises. For example, when the engineering department has to interact with the marketing department on a project, "the laws of physics collide with those of customer orientation and market. Misunderstandings are inevitable. Both hemispheres are so fundamentally different in terms of education, language and objectives" (Schütz \& Bloch, 2006: 33).

A functional frame is initially indoctrinated during the employee's formal education or training (Knudsen, 2001). It is further socialized through the employee's membership in professional associations (Morse \& Weiss, 1955). Additionally, in 
a typical U-form correer path, mobility generally is limited to advancement within the functional area, since employees tend to lack the expertise to move across functional areas (Hax \& Majluf, 1981). Thus, the functional frome is further reinforced throughout the career of the employee in a U-form organization. Together, these factors lead to high functional frome salience (strong functional frames) in a unitary hierarchy. This salience makes it is more difficult for the members of the two functional areas to negotiate a common dominant frame for a particular project because both groups have such strong nonoverlapping, incompatible views of the exchange (Gaertner, Mann, Murrell, \& Dovidio, 1989). Thus, interpretation-based conflict is highly likely to occur in a unitary hierarchy as a result of conflicting functional fromes.

M-form. An M-form is a hierarchy based on product divisions. For example, Procter \& Gamble has four product divisions: (1) health and grooming; (2) baby, feminine, and family care; (3) beauty, hair, and personal care; and (4) fabric and home care. The structural characteristics of a multidivisional hierarchy such as this lead to the emergence of division-level fromes (see the "Multidivisional" column in Table 1). First, employees from different functional areas are physically aggregated within a single product division, so they are more likely to be awore of product division membership than functional area membership (Turner et al., 1987). Additionally, product divisions are generally autonomous (Bercovitz et al., 2001), with members largely viewing other divisions as competition, which strengthens product group membership and increases the likelihood of a division-level frame. Division-level incentives also focus employees' attention on divisional performance rather than individual or functional performance (Ocasio, 1997), further emphasizing the product division view of the world. However, employees within different business units simultaneously maintain elements from their individual functional fromes. For example, each business unit has an accounting division and accountants in division A have very similar responsibilities to those of accountants in division B. Thus, when a project is conducted across project divisions, the actors' frames have some compatible functional elements and some common language to discuss the project. Finally, information in an M-form flows within divisions but not across them (Bercovitz et al., 2001), since competition between them creates little incentive to share information. Thus, divisional group membership is highly salient in multidivisional hierarchies, leading to strong division-level fromes. For example, when the music, video, and game divisions of Sony were tasked with creating an online delivery system, they each interpreted customer needs differently, leading to the creation of three different proprietory systems with different looks, feels, and user experiences, rather than a standardized platform.

Although divisional membership is fairly stable, employees in an M-form do occasionally move across project divisions in their career path (Gaertner, 1988), leading to greater exposure to other division-level frames. Exposure to alternative frames with compatible elements reduces the strength of division-level frames. Additionally, these frames are not indoctrinated through formal education or professional groups. Instead, the specific divisional frame only influences behavior as long as the person is employed within that particular division of a firm. Thus, division-level frames in an M-form are weaker (less salient) compared to the functional frames in a U-form hierarchy.

As a result of these structural elements, divisional frames are nonoverlapping, since they define how different divisions with distinct interests and goals view a common exchange. However, they are also compatible, because the frames contain similar functional elements and common language. Additionally, increased employee mobility in on M-form (as compared to a U-form) allows for exposure to different divisional fromes, leading to greater familiarity (Zajonc, 1968), which also supports greater compatibility. So although significant effort is still required to negotiate a common frame across these nonoverlapping frames (Kaplan, 2008), compatibility somewhat reduces this effort (Weber \& Mayer, 2014). As a result, interpretation conflict is still likely to occur in an M-form, although at a somewhat attenuated rate as compared to a U-form hierarchy.

Project matrix. Finally, a project matrix is structured by projects, rather than by products or functions. PricewaterhouseCoopers is an example of a firm that has a project matrix organization, with projects formed and then dissolved as they are completed. In a project matrix such as this one, individual frames emerge (see the "Project Matrix" column in Table 1). Individuals are usually either not physically segregated or temporarily segregated based on project team. Additionally, team membership is transient in this hierarchal 
form, since teams are usually disbanded when projects are complete, so depersonalization does not occur (Turner et al., 1987). Incentives in this type of matrix are also largely determined on the basis of individual performance within the project. The project manager generally uses his or her discretion to reward and punish personnel during the project (Mee, 1979: 33), and individual team members are reassigned to new teams based on their prior individual performance within a project team, as well as their area of specialty (Argyris, 1967). Both of these factors further reinforce the focus on individual-level performance. Finally, information flows within and between projects in a project matrix (Kuprenas, 2003). As specialists move throughout the organization, they bring their own view of the project to the team, based on their prior personal functional and project experience, further emphasizing individual-level views of the project.

Similar to a U-form hierarchy, a project matrix also creates a career path for specialists (Galbraith, 1971). However, unlike the U-form, "the development of career paths [is] based on multifunctional, multibusiness, and multicountry experiences" (Hax \& Majluf, 1981: 429), which are individual-level specializations, not general functional specialization. So this structural characteristic of a project matrix further strengthens employees' individual-level frames. In addition, the personal nature of individual fromes makes them highly salient in a project matrix hierarchy. These fromes are fomiliar to the individuals and have been reinforced over time (Benford \& Snow, 2000). Thus, individual fromes within a project matrix are strong and significantly influence behaviors and interpretation in project team task execution.

However, employees in a project matrix are skilled at negotiating a common dominant frame within the project team (Kuprenas, 2003). Because these individual fromes often do not coincide, individuals in a project matrix organization must have "strong communication skills and an ability to work in teams" (Kuprenas, 2003: 59) in order to be able to "establish a common language and understanding of management processes" (Kuprenas, 2003: 60). As a result, they develop the absorptive capacity (Cohen \& Levinthal, 1990) required to continually create compatible frame elements within their project team (Benford \& Snow, 2000). Additionally, negotiating a common dominant frame is much more feasible in a small team than across functional or product divisions because there are fewer people who need to be recruited to the dominant view of the exchange (Weber \& Mayer, 2014). Project team employees are also likely to have compatible elements in their individual frames, having worked with other cross-functional teams and having already adapted their individual fromes in prior projects. Because of these properties, a common dominant frame is easier to develop within a project group in this matrix form than across functions or divisions in a U-form or M-form hierarchy. As a result, employees in a project matrix are least likely to experience interpretation conflict in an intraorganizational exchange.

Proposition 1: When a transaction is governed by a project matrix, the parties are less likely to experience interpretation-based conflict than when governed by a unitary or multidivisional hierarchy.

\section{Role-Based Conflict}

Although conflicting interpretations generally arise when frames are incompatible, we argue that another type of misinterpretation can arise if frames contain compatible elements. Role-based conflict occurs when two parties simultaneously believe they own the same part of the exchange, leading to internal turf wars (Cannon, Achrol, \& Gundlach, 2000). ${ }^{6}$ Role-based conflict is highly likely when (l) two parties work together on a project in which task responsibilities are not clearly specified and (2) each party assumes that the other agrees with its assessment of roles in the exchange owing to the social projection heuristic (Allport, 1924). Transaction costs arise from rolebased conflict because the two parties feel justified laying claim to the task based on their view of their responsibilities (their frame). When role conflict occurs, one exchange party can misinterpret the other's intentions, leading to accusations of opportunistic behavior (e.g., shirking or holdup), even when none was intended. Additionally, transaction costs arise from duplication of effort in the exchange and delay of the project, or even negative exchange performance. We

\footnotetext{
${ }^{6}$ For example, both the print circulation and digital distribution units of the New York Times believed they had jurisdiction to control pricing and distribution of the paper's proprietary iPad content, which led to conflict between the units (Tate, 2010).
} 
argue that role conflict is a substantial issue in internal exchanges, since it has a significant negative impact on organizational performance (Herrera, Reuben, \& Ting, 2014).

Role conflict is traditionally on issue under contractual governance because contracts are unintentionally incomplete, owing to bounded rationality (Williamson, 1985). In contrast, hierarchy is viewed as reducing role conflict because

every position in a formal organizational structure should have a specified set of tasks or position responsibilities. Such specification of duties, or formal definition of role requirements, is intended to allow management to hold subordinates accountable for specific performance and to provide guidance and direction for subordinates (Rizzo, House, \& Lirtzman, 1970: 151).

Additionally, fiat is available to resolve any remaining disagreements over roles or responsibilities in an exchange (Williamson, 1991, 1998). However, hierarchy may actually exacerbate role conflict rather than attenuate it.

Within hierarchy, two forces influence role conflict. First, when two individuals share compatible but nonoverlapping definitions of the exchange, they may believe that they are responsible for the same tasks (e.g., Goffman, 1974; Kaplan, 2008). Second, the problems of role ambiguity can be exacerbated by social projection (Allport, 1924), an egocentric bias in which people overestimate the frequency that others have the same interpretations, judgments, and values as they do. Social projection occurs more often when the parties see themselves as similar, such as when outgroup salience and/or competition between groups or individuals is lower (Clement \& Krueger, 2002; Robbins \& Krueger, 2005). Together, these cognitive factors prevent the actors from questioning whether their own interpretation of exchange responsibilities is shared by the other parties in the exchange. As a result, each party acts on its own interpretation, which leads to role conflict. However, different hierarchical forms promote varying levels of frame compatibility and social projection, suggesting that some forms are more efficient than others at attenuating role conflict.

U-form. Functional-level frames, which develop in a unitary hierarchy, are largely nonoverlapping and incompatible because they do not contain any of the same information, or even similar information about the exchange (Weber \& Mayer, 2014). Additionally, ingroup and outgroup membership are very salient in a U-form hierarchy because the functional groups are very distinct. Social projection is much stronger toward ingroup members than individuals who are clearly in the outgroup (Clement \& Krueger, 2002; Robbins \& Krueger, 2005). As a result, a unitary hierorchy reduces the likelihood of ambiguous roles in an exchange and attenuates social projection, decreasing the likelihood that people will act on their different role interpretations if role definitions are slightly ambiguous. Instead, we argue that members of different functional groups are likely to pause to clorify who is responsible for a particular aspect of the project, further reducing the possibility of role conflict under a unitary hierarchy.

M-form. In contrast, multidivisional forms lead to the development of divisional frames, which are nonoverlapping. Yet divisional frames are still compatible, since they contain common functional elements (Galbraith, 1971). Thus, when on internal project spans business units in an M-form, the frames contain compatible role responsibilities, leading to role ambiguity in the exchange. Moreover, employees in a multidivisional hierarchy are somewhat more mobile than in a unitary hierarchy (Gaertner, 1988), leading to greater exposure to different division-level frames, which also increases frame element compatibility (Weber \& Mayer, 2014), thus further exacerbating role conflict.

Compatible project division frames also blur the distinction between the ingroup and outgroup. The reduction in outgroup salience increases the likelihood that employees in one business unit will project their beliefs onto members of another business unit (Clement \& Krueger, 2002; Robbins \& Krueger, 2005). So when role ambiguity arises because of the overlapping frame elements, the employees in an M-form are more likely to act on their own role interpretations, in the assumption that others share these views. For example, if the content and software divisions of a firm have been tasked with creating an app to deliver original content, programmers in both the divisions may claim responsibility for creating the functionality for the app, leading to conflict. As a result, multidivisional hierarchy significantly increases the chance of role conflict in an intraorganizational exchange.

Project matrix. Finally, under a project matrix, employees develop individual frames, which contain elements of all of the responsibilities they have had during their time in the firm. These individual frames contain functional frame elements. However, because more than one person 
from a functional area is on a single project team, the role a person plays in a project may be decoupled from his or her traditional functional role (Galbraith, 1971), leading to role ambiguity. Individual frames also contain compatible role elements, which increase the likelihood of social projection, since the similarities rather than the differences between the individuals are highlighted. Additionally, because attention is focused at the individual level, an outgroup does not exist. Instead, the other employees that an individual is working with are all on the same team, so the individual is more likely to assume that his or her team members will view project responsibilities in the same way he or she does (Clement \& Krueger, 2002; Robbins \& Krueger, 2005), further increasing the likelihood of social projection. For example, role conflict may occur in a project matrix when a marketing person, who has experience using customer feedback to shape product features in an initial project, is subsequently assigned to a different team along with an engineer who believes that developing product features is her role. As a result, the potential for role conflict is significantly increased under a project matrix organization.

Proposition 2: When a transaction is governed by a unitary hierorchy, the parties are less likely to experience role-based conflict than when governed by a multidivisional or project matrix hierarchy.

\section{Evaluation-Based Conflict}

According to Ouchi (1980: 130-131), it is the "demand for the perception of equity that generates transactions costs" (Husted \& Folger, 2004: 721). When it is difficult to determine each party's contribution to a task, a perception of equity is absent, leading to evaluation-based conflict. This conflict is further exacerbated when incentives are tied to contribution level. Yet it is often unintentional, resulting from individual- and/or group-level biases in estimating ability or share of responsibility for task success, rather than blatant opportunism.

At the individual level, superiority bias (e.g., Alicke \& Govorun, 2005) leads individuals to systematically overestimate their own abilities. For example, in one survey over 80 percent of U.S. college students indicated that they believed they were in the top 50 percent of safe drivers (Svenson, 1981). This lack of self-awareness can arise when individuals lack the skills to recognize they are making errors and instead draw conclusions about their own performance from preconceived ideas about their skill level (Dunning, Johnson, Ehrlinger, \& Kruger, 2003). It con also stem from recall biases, in which others' performances are systematically but unconsciously remembered more conservatively thon an individual's own performance. Thus, the individual honestly believes his or her own performance is superior to that of others (Hilbert, 2012).

Relatedly, two individual-level cognitive biases lead to conflict when parties evaluate responsibility for an outcome. First, when two parties contribute to a task, egocentric bias (Ross \& Sicoly, 1979) leads each to claim a greater share of the contribution to the success of the project than on independent observer would assign. "Such 'egocentric interpretations' of fairness (Messick \& Sentis, 1985) interfere with dispute resolution because people are averse to settling for what they consider to be an unfair agreement (Loewenstein, Thompson, \& Bazerman, 1989)" (Thompson \& Loewenstein, 1992: 177). Second, self-serving bias (Heider, 1958) suggests that individuals tend to claim greater responsibility for successes than failures. As in the case of superiority bias, these inflated claims may not actually be opportunistic, although the other party may interpret them as such.

At the group level, ingroup bias (Brewer \& Campbell, 1976; Tajfel, Billing, Bundy, \& Floment, $1971)$ is the tendency for people to evaluate members of their own groups more favorably than members of other groups. This treatment includes positively interpreting ambiguous ingroup member behavior and awording ingroup members more resources. In addition, group-serving bias (Forsyth \& Schlenker, 1977; Taylor \& Doria, 1981) occurs when group members make internal attributions for their group's positive behavior and external attributions for their group's negative behavior, and vice versa for outgroups. Together, these two group-level biases lead ingroup members to unintentionally (or intentionally, if accompanied by opportunism) claim a greater share of success or effort than worronted, creating evaluation-based conflict. As with interpretation conflicts, choice of hierarchical form directly impacts whether evaluation-based conflict is magnified or reduced in the exchange through differences in individual or group identity activation, group membership stability, referent groups, and referent group salience.

U-form. As established above, unitary hierarchy activates functional-level identities, leading to group-level social comparisons (see the 
"Unitary" column in Table 2). The physical division of specialists in the U-form (Galbraith, 1971) highlights the element of "us versus them," increasing the feeling of belonging to a particular functional group (Hogg \& Terry, 2000). Additionally, the functional-level incentives activate this group identity by focusing attention on the performance of the functional area in comparison to others (Vancil, 1978). U-form employees also generally stay within a particular functional group throughout their career (Gouertner, 1988). This long-term group membership further highlights a grouplevel functional identity (Brewer \& Gordner, 1996; Hogg \& Turner, 1985; Turner, 1982).

The sense of competition between the groups also makes the other functional areas natural referents for comparison (Friedkin \& Simpson, 1985). Differences between the functional areas are further exaggerated because information flows within a functional group but not across groups (Bercovitz et al., 2001), allowing "stereotypes [to] take root and flourish" (Schütz \& Bloch, 2006: 36). Stereotypes are also easily adopted in a U-form because they are well-established in society (Pelled \& Adler, 1994). ${ }^{7}$ As a result, functional group membership and referent groups are highly salient in unitary hierarchies (Brickson, 2000), so social comparison biases at the functional group level are highly likely to occur in a unitary hierarchy.

Functional group comparison invokes ingroup bias (Brewer \& Campbell, 1976; Tajfel et al., 1971) and group-serving bias (Forsyth \& Schlenker, 1977; Taylor \& Doria, 1981). Under these biases, an individual in a U-form hierarchy sees his or her own functional ingroup members' behaviors more favorably and attributes this positive behavior to desirable group characteristics, while simultaneously viewing outgroup behavior less favorably and assuming outgroup members' positive behavior arises from external factors. So, in a U-form, members of one functional group may unintentionally claim a greater share of success or effort than they actually deserve, increasing the likelihood of evaluation-based conflict within the interorganizational exchange. For example, when a new product is successfully launched, $\mathrm{R} \& \mathrm{D}$ may credit its innovative technology for strong sales, while marketing may attribute these

\footnotetext{
${ }^{7}$ An example is the common adage "How can you tell a salesman is lying? His lips are moving" (Pelled \& Adler, 1994: 24).
}

same sales to its novel cormpaign, resulting in conflict about who deserves the largest portion of the bonuses tied to product performance.

M-form. The multidivisional form physically segregates employees into product divisions (Bercovitz et al., 2001), which highlights group membership at a divisional rather than functional level (Hogg \& Terry, 2000). Division-level incentives further support the activation of a product division identity (Vancil, 1978). However, an M-form career path, which cuts across functional areas but remains largely within the same project division, allows for somewhat more mobility between divisions than does a U-form (Gaertner, 1988), weakening the activation of this identity. Additionally, employees adopt a production division identity only during their tenure within the division, not during their formal education, which also results in lower group-level identity salience in a multidivisional hierorchy thon in a unitary hierarchy (Hogg \& Turner, 1985; see the "Multidivisional" column in Table 2).

Similar to the U-form, competition between the groups makes other project divisions the natural basis for comparison (Friedkin \& Simpson, 1985). In an $\mathrm{M}$-form, information also flows within divisions, but not across them (Bercovitz et al., 2001). As noted above, different product divisions still contain common functional information, so it is less likely that group stereotypes will be embraced (Schütz \& Bloch, 2006). Additionally, product divisions are somewhat unique to the firm, so established stereotypes of each group do not usually exist at a societal level. As a result, although divisional group membership is still salient in multidivisional hierarchies, the differences are not as strongly highlighted, so the referent groups are less salient than in a U-form.

Because a group identity is activated, parties to a hierarchical exchange are not comparing themselves to other individuals in the exchange. They are therefore unlikely to fall prey to superiority, egocentric, or self-serving biases. Additionally, because referent group salience is weaker than that in the U-form, group-level social comparison biases, such as ingroup (Brewer \& Campbell, 1976; Tajfel et al., 1971) or group-serving bias (Forsyth \& Schlenker, 1977; Taylor \& Doria, 1981), will be less likely to occur as compared to the U-form. As a result, evaluation-based conflict is attenuated under multidivisional hierarchy.

Project matrix. In contrast, a project matrix invokes an individual-level identity, leading to 
social comparisons with other people, as opposed to other groups (see the "Project Matrix" column in Table 2). First, a project matrix hierarchy divides employees into temporary project teams (Argyris, 1967). However, the transitory nature of project teams leads to activation of individual-level identities rather than group identities (Brickson, 2000), since group delineations are not highly salient. In addition, incentives are largely determined on the basis of individual performance in a project matrix (Argyris, 1967), so individual identities ore further highlighted. As specialists move throughout the organization, they bring unique information to the team, based on their own prior personal functional and project experience. Thus, this organizational structure encourages the development and dissemination of individual-level information. The importance of this distinct information to project success further supports an individual identity in the project matrix form (Brewer \& Gardner, 1996).

"When a personal [individual] identity orientation is primed (activated or made salient), people... utilize comparisons with other individuals as a frame of reference" (Brickson, 2000: 84). In addition, structural factors of the project matrix further increase the salience of an individual-level referent. First, employees compete against all other employees for rewards and desirable assignments in this hierorchal form (Friedkin \& Simpson, 1985). This competition is further highlighted by career paths for individual specialists (Galbraith, 1971; Hax \& Majluf, 1981), who advance based on the aggregation of their professional experiences. So the individual as the referent is highly salient in a project matrix.

As a result of activation of an individual-level identity and highly salient individual referents, employees in a project matrix are subject to individual-level social comparison biasesspecifically, superiority (e.g., Alicke \& Govorun, 2005), egocentric (Ross \& Sicoly, 1979), and selfserving biases (Heider, 1958). Together, these biases prompt an overestimation of individual abilities and claims of greater contribution or success than warranted, suggesting that evaluation-based conflict is highly likely in this hierarchal form. For example, when two software developers on a project team jointly design a highly innovative new product, they may spend significant time and effort shaping management's perceptions of their individual roles in the project's success.
Proposition 3: When a transaction is governed by a multidivisional hierarchy, the parties are less likely to experience evaluation-based conflict than when governed by a unitary or project matrix hierarchy.

\section{Asset Specificity}

Although the transactions considered here are high in traditional TCE transaction dimensions (asset specificity, uncertainty, and frequency), variations can still exist. It is important to examine how adding bounded rationality-based transaction costs to TCE impacts these key elements. We argue that both uncertainty and asset specificity play additional roles when these new costs are considered.

By expanding TCE's bounded rationality assumption with heuristics and cognitive biases, we augment Weber and Mayer's (2014) previous work, which adds frames to TCE, leading to an expansion of the uncertainty concept. Weber and Mayer argue that when frames are considered, both classic environmental uncertainty (informational) and interpretive uncertainty, arising from differences in parties' fromes, impact the governance decision. They further suggest that interpretive uncertainty is generally attenuated under hierorchy. ${ }^{8}$ Our study exponds their idea of interpretive uncertainty in two ways. First, we suggest that if more complex hierarchal forms are considered, interpretive uncertainty may also arise in intrafirm exchanges. Second, we suggest that in addition to frames, interpretive uncertainty can arise from other heuristics, such as stereotypes, as well as from cognitive biases.

In addition, expanding the bounded rationality assumption creates a different role for asset specificity than in opportunism-centric TCE. Traditionally, unilateral asset specificity increases the likelihood of holdup, since once one party makes a commitment to the transaction, the other may hold out for additional payment owing to the partner's unilateral commitment to the exchange (Williamson, 1985). However, when the bounded rationality assumption is augmented with heuristics and cognitive biases, unilateral asset

\footnotetext{
${ }^{8}$ They also stipulate that informational uncertainty is a key prerequisite for interpretive uncertainty, since it increases preexisting ambiguity in the exchange. Thus, greater informational uncertainty leads to greater interpretive uncertainty.
} 
specificity increases the salience of frame differences. That is, when one party makes an irreversible commitment to the exchange, the differences between the parties are highlighted, increasing the "us versus them" element of the exchange (Ashforth \& Mael, 1989), because one party is now in a more vulnerable position than the other. As a result, increasing frame salience raise the overall level of frame-based conflict in the exchange, irrespective of hierarchal form. Additionally, because unilateral asset specificity highlights the parties' differences, individuals are more aware of the boundaries between their group and the outgroup or the other individuals who are their basis for comparison in the exchange (Wilder, 1981). Thus, conflict based on social comparison biases also increases in the exchange, regardless of hierarchal form.

Proposition 4a: Increasing unilateral asset specificity leads to greater levels of bounded rationality-based conflict in an internal transaction.

However, the opposite occurs when asset specificity increases on both sides of the internal transaction (Williamson, 1985). Bilateral transactionspecific investments-that is, joint commitments to a shared project-may increase the "we are in the same boat" dimensions of the exchange, lowering both frome and referent salience. Specifically, partners have a high degree of common interest and their strategies are strongly complementary, which may lead them to adopt collective goals as their own (Bacharach, 2006). Thus, bilateral asset specificity tends to reduce bounded rationality-based transaction costs in an exchange.

Proposition 4b: Bilateral asset specificity leads to lower levels of bounded rationality-based conflict in an internal transaction.

\section{DISCUSSION}

Our main aim in this article is to move bounded rationality more to the explanatory front seat in the understanding of economic organization by arguing that it cause costly conflict that can exist entirely independent of opportunism. Thus, a key implication is that bounded rationality alone is sufficient to discriminate in a transaction costminimizing way between alternative hierarchical forms. In contrast, many scholars hold that the assumption of opportunism is strictly necessary for explaining complex contracting and hierarchy. Williamson is explicit on this issue:

The incentive, control, and contract law differences that define alternative modes of governance ... all vanish if opportunism is zeroed out. Thus (1) no incentive differences will appear because all members of every group subscribe to the same "general clause" and implement the same objective function in the same fully committed way; (2) all costeffective regularities (practices and procedures) that are adopted by one group will also be adopted by another-whatever the nominal form of organization (private firm, public bureau, nonprofit, autonomous market) from which they start; and (3) contract law differences serve no purpose among groups all of which share the same purpose and converge to the same form. Note, moreover, that ... conflict and haggling . . . will never appear in opportunism-free groups . . . every such group will work out its differences instrumentally (1999: 1099).

We do not question that if, indeed, all members of a group "implement the same objective function in the same fully committed way," there will be only trivial problems of complex contracting and hierarchical form left. However, saying that opportunism is absent does not commit one to the assumption that members share a common objective function and that all implement it in a fully committed way. Thus, self-interested but nonopportunistic members may not implement the same objective function and may exhibit different degrees of commitment to joint goals. We therefore argue that it is not correct that "conflict and haggling . . . will never appear in opportunism-free groups." On this issue we side with Alchion and Woodward, who in a review of Williamson (1985) argued that

even when both parties recognize the genuine goodwill of the other, different but honest perceptions can lead to disputes that are costly to resolve. The point is important because many business arrangements interpreted as responses to potential "dishonest" opportunism are equally appropriate for avoiding costly disputes between honest, ethical people who disagree about what event transpired and what adjustment would have been agreed to initially had the event been anticipated (1988: 66).

We have identified additional bounds on rationality (cognitive economizing and biases) from the relevant cognitive and social psychology literature that shed light on how costly disagreements and subsequent conflict can develop "between honest, ethical people," which informs our understanding of the cognitive liabilities of 
hierorchies. Thus, by highlighting the effects of heuristics and cognitive biases that arise within and between individuals and groups in different hierarchical forms, we can better identify how hierarchy impacts problems caused by bounded rationality. This insight allows us to make novel predictions concerning which types of hierarchical forms inherently increase or reduce specific types of conflicts based on bounded rationality rather than opportunism.

Note that we do not argue that opportunism does not exist within hierarchy. In fact, we agree that it is an important element in governance decisions. However, we focus on an alternative source of transaction costs that have been largely omitted from this decision. It may also well be the case that there are subtle interaction effects between bounded rationality-based conflict and more traditional opportunism-driven conflicts featured in the organizational economics literature. This topic would be an interesting one to explore in future research.

\section{Complementing and Strengthening TCE}

Although we hold that the analysis of hierarchical form will benefit from a richer conception of bounded rationality than has traditionally informed TCE, and that too much emphasis may have been placed on opportunism, this article is best seen as an extension of TCE reasoning. We do focus on an unconventional source of transaction costs. Yet we still suggest that transaction costs can be minimized by selecting the most efficient governance form, and we argue that different hierarchical forms have different capacities for mitigating (bounded rationality-based) transaction costs.

In fact, we see the ideas in this article as strengthening TCE's position against key critiques (cf. Gibbons, 2010). For example, Grossman and Hart (1986) hold that TCE exaggerates the ability of hierarchy to attenuate conflicts and process information, and they question the usefulness of the bounded rationality assumption (Hart, 1995). Williamson comments that the logic underlying their critique "vaporize[s] ex post maladaptation by [the] assumptions of common knowledge and costless ex post bargaining" (2000: 605). Common knowledge (e.g., $\mathrm{A}$ knows $\mathrm{x}, \mathrm{B}$ knows that $\mathrm{A}$ knows $\mathrm{x}, \mathrm{A}$ knows that $B$ knows that $A$ knows $x, \ldots$ ad infinitum), a key assumption in most formal organizational economics, flies in the face of bounded rationality (Kreps, 1996). Thus, Williamson invokes an argument rooted in bounded rationality to criticize the argument that hierarchy has no particular information-handling advantages.

In the context of this discussion, our contribution further strengthens Williamson's position. By drawing on the cognitive literature and social psychology literature, we argue that biases and frames make "ex post bargaining" anything but costless, since the parties may still arrive at different interpretations, even if they possess the same information. Additionally, our analysis suggests that traditional TCE is often rooted in a simplistic understanding of hierarchical governance, where "hierarchy" is compared to "hybrid" and "market." While scholars increasingly understand that hybrid forms are multidimensional, the same recognition has not yet been achieved for other governance forms within the theory. By both augmenting the bounded rationality assumption and digging deeper to understand how hierarchical forms are inherently linked to bounded rationality-based conflicts, we can better understand internal transaction costs-long a criticism of TCE (e.g., Gibbons, 2010: 279; Holmström \& Roberts, 1998; Nickerson \& Zenger, 2008)—and refine our understanding of the transaction cost implications of different hierarchical forms. As a result, we can offer more precise governance predictions based on transaction cost logic, as achieved in further dimensionalizing hybrid governance forms.

\section{Future Research}

Although the integration of social psychological features of hierarchical transactions with TCE arguably began with Ouchi (1980), very few scholars have pursued this line of research (e.g., Husted \& Folger, 2004; Nickerson \& Zenger, 2008; Weber \& Mayer, 2014). We have extended this literature by identifying heuristic and cognitive bias effects that may cause transaction costs inside hierarchies. While we have focused on those biases and framing effects that we consider to be most immediately relevant for understanding the social psychological forces that influence such costs, the body of literature on heuristics and biases is very large, so no doubt others beyond those we have discussed in this article will also have a significant influence on the costs of hierarchy. Findings on social desirability seem particularly relevant, since hierarchal form may determine the extent to which different social desirability norms exist within on organization. Decentralized forms may allow for 
more diversity, which may lead to higher internal transaction costs. Relatedly, we have only scratched the surface of attribution theory with our discussion of self-serving bias; however, hostile attribution biases (i.e., individuals' tendencies to interpret others' ambiguous behaviors as hostile) may also differ across hierarchical forms. The variety in interpretation depends on how such biases arise under functional or product division frames, an issue the research literature is silent about, but which calls for future research.

Moderating factors at different levels may also intervene at each step in our argument. In effect, we have held such factors constant, but future research should take them into account. For example, communities of practice-which may cut across hierarchical organization (e.g., the same community may span several divisions)_can be a factor moderating the extent to which frames and verbal codes are associated with hierarchical costs. On a higher level, factors like industry and technological dynamism and turbulence may also be important moderating factors. In turbulent environments there is a need for fast managerial decision making. Fast decision making is more likely to rely on heuristics and readily available frames and is, as such, more likely to be prone to cognitive biases, particularly when novel situations are involved.

Although we have provided a theory of hierarchical transaction costs, we have not taken the step toward developing a full-blown theory of discriminating alignment. That is to say, while we have theorized how conflict rooted in bounded rationality varies systematically with different hierorchical forms, we have not characterized the transactions organized by hierarchy beyond what TCE offers on the issue. This means that we have not theorized which hierarchical form will most efficiently govern an internal transaction with certain characteristics. Developing such a theory requires that transactions be dimensionalized in ways that go beyond classical TCE (Williamson, 1985; see, for example, Mayer \& Nickerson, 2005, and Nooteboom, 2004).

Finally, we recognize that hierarchical forms evolve through path-dependent processes (Argyres \& Liebeskind, 1999) and consist of complementary elements (Williamson, 1996). This means that hierarchical forms cannot always be molded to fit transactions, at least in the short run. Thus, Argyres and Liebeskind (1999) argue that prior governance decisions limit a firm's ability to change its governance structure, which they call governance inseparability. Therefore, the hierarchal structure that a firm has previously committed to may prevent managers from pursuing particular transactions that may misalign with that structure. As a result, in the long term the firm will likely avoid these transactions, since it may not be able to address the costs that its particular hierorchal form creates. Alternatively, it may take additional steps to mitigate bounded rationality-based conflict. For example, firms can take steps to reduce interpretationbased conflict in U-forms or M-forms by creating special task forces around the relevant transactions that include employees from the involved functions or product divisions, or by establishing formalized knowledge-sharing programs that may reduce interpretive ambiguity.

\section{CONCLUSION}

The TCE and psychology research streams that we draw on are complex and rich in terms of constructs and findings. Bringing them into direct contact may seem to be a difficult and risky venture. However, by starting from key findings in the relevant bodies of psychology literature that are likely to have a bearing on hierarchical organization, we theorize how these cognitive influences may produce conflict that, in turn, gives rise to costs of conducting transactions internally. Following basic TCE logic, we then show how specific hierarchical forms may mitigate these problems, thus extending the TCE approach to treating organization as an "instrument for utilizing varying cognitive and behavioral propensities to best advantage" (Williamson, 1998: 12). Our propositions demonstrate that this program produces new insight in hierarchical organization.

\section{REFERENCES}

Alchian, A. A., \& Woodword, S. 1988. The firm is dead; long live the firm: A review of Oliver E. Williamson's The economic institutions of capitalism. Journal of Economic Literature, 26: 65-79.

Alicke, M. D., \& Govorun, O. 2005. The better-than-average effect. In M. D. Alicke, D. Dunning, \& J. I. Krueger (Eds.), The self in social judgment: 85-105. New York: Psychology Press.

Allport, F. H. 1924. Social psychology. Boston: Houghton Mifflin.

Argyres, N., \& Liebeskind, J. P. 1999. Contractual commitments, bargaining power, and governance inseparability: 
Incorporating history into transaction cost theory. Academy of Management Review, 24: 49-63.

Argyris, C. 1967. Today's problems with tomorrow's organizations. Journal of Management Studies, 4: 31-55.

Ashforth, B. E., \& Mael, F. 1989. Social identity theory and the organization. Academy of Management Review, 14: 20-39.

Bacharach, M. 2006. Beyond individual choice: Teams and frames in game theory. (Edited by N. Gold \& R. Sugden.) Princeton, NJ: Princeton University Press.

Bateson, G. 1972. Steps to an ecology of the mind. New York: Ballantine Books.

Benford, R. D., \& Snow, D. A. 2000. Framing processes and social movements: An overview and assessment. Annual Review of Sociology, 26: 611-639.

Bercovitz, J., Feldman, M., Feller, I., \& Burton, R. 2001. Organizational structure as a determinant of academic patent and licensing behavior: An exploratory study of Duke, Johns Hopkins, and Pennsylvania State Universities. Journal of Technology Transfer, 26: 21-35.

Bodenhausen, G. V., \& Wyer, R. S. 1985. Effects of stereotypes in decision making and information-processing strategies. Journal of Personality and Social Psychology, 48: 267-282.

Brewer, M. B., \& Campbell, D. T. 1976. Ethnocentrism and intergroup attitudes: East African evidence. New York: Halstead Press.

Brewer, M. B., \& Gardner, W. 1996. Who is this "we"? Levels of collective identity and self representations. Journal of Personality and Social Psychology, 71: 83-93.

Brickson, S. 2000. The impact of identity orientation on individual and organizational outcomes in demographically diverse settings. Academy of Management Review, 25: 82-101.

Bromiley, P., \& Harris, J. 2006. Trust, transaction cost economics, and mechanisms. In R. Bachmann \& A. Zaheer (Eds.), Handbook of trust research: 124-143. Northampton, MA: Edward Elgar.

Cannon, J. P., Achrol, R. S., \& Gundlach, G. T. 2000. Contracts, norms, and plural form governance. Journal of the Academy of Marketing Science, 28: 180-194.

Chandler, A. D. 1962. Strategy and structure: Chapters in the history of the American industrial enterprise. Cambridge, MA: MIT Press.

Clement, R. W., \& Krueger, J. 2002. Social categorization moderates social projection. Journal of Experimental Social Psychology, 38: 219-231.

Cohen, W. M., \& Levinthal, D. A. 1990. Absorptive capacity: A new perspective on learning and innovation. Administrative Science Quarterly, 35: 128-152.

Cowan, N. 2000. Processing limits of selective attention and working memory: Potential implications for interpreting. Interpreting, 5: 117-146.

Cronin, M. A., \& Weingart, L. R. 2007. Representational gaps, information processing, and conflict in functionally diverse teams. Academy of Management Review, 32: 761-773.

Dunning, D., Johnson, K., Ehrlinger, J., \& Kruger, J. 2003. Why people fail to recognize their own incompetence. Current Directions in Psychological Science, 25: 154-177.
Dutton, J. E., \& Jackson, S. E. 1987. Categorizing strategic issues: Links to organizational action. Academy of Management Review, 12: 76-90.

Entman, R. M. 1993. Framing: Toward clarification of a fractured paradigm. Journal of Communication, 43: 51-58.

Evans, R. 2008. The handbook of biopharma industry acronyms \& terms. Sudbury, MA: Jones \& Bartlett Publishers.

Feather, J. 1999. The information society: A study of continuity and change. Library Quarterly: Information, Community, Policy, 69: 275-277.

Fiske, S. T., \& Taylor, S. E. 1991. Social cognition (2nd ed.). New York: McGrow-Hill.

Forsyth, D. R., \& Schlenker, B. R. 1977. Attributional egocentrism following performance of a competitive task. Journal of Social Psychology, 102: 47-52.

Foss, N. J. 2003. Bounded rationality in the economics of organization: Much cited and little used. Journal of Economic Psychology, 24: 245-264.

Fox, C. R., \& Tversky, A. 1995. Ambiguity aversion and comparative ignorance. Quarterly Journal of Economics, 110: 585-603.

Friedkin, N. E., \& Simpson, M. J. 1985. Effects of competition on members' identification with their subunits. Administrative Science Quarterly, 30: 377-394.

Gaertner, K. N. 1988. Managers' careers and organizational change. Academy of Management Executive, 2(4): 31 1-318.

Gaertner, S. L., Mann, J., Murrell, A., \& Dovidio, J. F. 1989. Reducing intergroup bias: The benefits of recategorization. Journal of Personality and Social Psychology, 57: 239-249.

Galbraith, J. R. 1971. Matrix organization designs: How to combine functional and project forms. Business Horizons, 14(1): 29-40.

Gibbons, R. 2010. Transaction-cost economics: Past, present and future? Scandinavian Journal of Economics, 112: 263-288.

Gigerenzer, G. 2003. Why does framing influence judgment? Journal of General Internal Medicine, 18: 960-961.

Gigerenzer, G., \& Todd, P. M., \& ABC Research Group. 1999. Simple heuristics that make us smart. Oxford: Oxford University Press.

Goffman, E. 1974. Frame analysis: An essay on the organization of experience. New York: Harper \& Row.

Grossman, S. J., \& Hart, O. D. 1986. The costs and benefits of ownership: A theory of vertical and lateral integration. Journal of Political Economy, 94: 691-719.

Hart, O. D. 1995. Firms, contracts, and financial structure. Oxford: Clarendon Press.

Hax, A. C., \& Majluf, N. S. 1981. Organizational design: A survey and an approach. Operations Research, 29: 417-447.

Heider, F. 1958. The psychology of interpersonal relations. Hillsdale, NJ: Lawrence Erlbaum Associates.

Herman, J. B., Dunham, R. B., \& Hulin, C. L. 1975. Organizational structure, demographic characteristics, and employee responses. Organizational Behavior and Human Performance, 13: 206-232. 
Herrera, H., Reuben, E., \& Ting, M. M. 2014. Turf wars. Working paper, HEC Montreal. Available at http://papers.ssrn.com/ sol3/papers.cfm?abstract_id $=2520740$.

Hilbert, M. 2012. Toward a synthesis of cognitive biases: How noisy information processing can bias human decision making. Psychological Bulletin, 138: 211-237.

Hogg, M. A., \& Terry, D. I. 2000. Social identity and selfcategorization processes in organizational contexts. Academy of Management Review, 25: 121-140.

Hogg, M. A., \& Turner, J. C. 1985. Interpersonal attraction, social identification and psychological group formation. European Journal of Social Psychology, 15: 51-66.

Holmström, B., \& Roberts, J. 1998. The boundaries of the firm revisited. Journal of Economic Perspectives, 12: 73-94.

Husted, B. W., \& Folger, R. 2004. Fairness and transaction costs: The contribution of organizational justice theory to an integrative model of economic organization. Organization Science, 15: 719-729.

Isenberg, D. J. 1986. Group polarization: A critical review and meta-analysis. Journal of Personality and Social Psychology, 50: 1141-1151.

Jones, E. E., \& Harris, V. A. 1967. The attribution of attitudes. Journal of Experimental Social Psychology, 3: 1-24.

Kahneman, D., \& Tversky, A. 1979. Prospect theory: An analysis of decisions under risk. Econometrica, 47: 263-291.

Kaplan, S. 2008. Framing contests: Strategy making under uncertainty. Organization Science, 19: 729-752.

Knudsen, T. 2001. Firm-specific cognitive frames as codeterminants of persistent performance differentials. Working paper, University of Southem Denmark, Odense University.

Kreps, D. M. 1996. Markets and hierarchies and (mathematical) economic theory. Industrial and Corporate Change, 5: 561-595.

Kuprenas, J. A. 2003. Implementation and performance of a matrix organization structure. International Journal of Project Management, 21(1): 51-62.

Lisman, J. E., \& Idiart, M. A. 1995. Storage of 7+/-2 short-term memories in oscillatory subcycles. Science, 267: 1512-1515.

Loewenstein, G., Thompson, L., \& Bazerman, M. H. 1989. Social utility and decision making in interpersonal contexts. Journal of Personality and Social Psychology, 57: 426-441.

Mahoney, J., \& McGahan, A. 2007. The field of strategic management within the evolving science of strategic organization. Strategic Organization, 5: 79-99.

March, J. G. 1994. A primer on decision-making. New York: Free Press.

March, J. G., \& Simon, H. A. 1958. Organizations. New York: Wiley.

Mayer, K. J., \& Argyres, N. S. 2004. Learning to contract: Evidence from the personal computer industry. Organization Science, 15: 394-410.

Mayer, K. J., \& Nickerson, J. A. 2005. Antecedents and performance implications of contracting for knowledge workers: Evidence from information technology services. Organization Science, 16: 225-242.
Mee, J. F. 1979. Ideational items. In R. Hill \& B. J. White (Eds.), Matrix organization \& project management: 32-35. Ann Arbor: University of Michigan.

Messick, D., \& Sentis, K. P. 1985. Estimating social and nonsocial utility functions from ordinal data. European Journal of Social Psychology, 15: 389-399.

Milgrom, P., \& Roberts, J. 1992. Economics, organizations, and management. New Haven, CT: Prentice-Hall.

Morse, N. C., \& Weiss, R. S. 1955. The function and meaning of work and the job. American Sociological Review, 20: 191-198.

Mumby, D. K., \& Putnam, L. L. 2002. The politics of emotion: A feminist reading of bounded rationality. Academy of Management Review, 17: 465-486.

Newell, A., \& Simon, H. A. 1972. Human problem solving. Englewood Cliffs, NJ: Prentice-Hall.

Nickerson, J. A., \& Zenger, T. R. 2004. A knowledge-based theory of the firm-The problem-solving perspective. Organization Science, 15: 617-632.

Nickerson, J. A., \& Zenger, T. R. 2008. Envy, comparison costs, and the economic theory of the firm. Strategic Management Journal, 29: 1429-1449.

Nooteboom, B. 2004. Governance and competence: How can they be combined? Cambridge Journal of Economics, 28: 505-525.

Ocasio, W. 1997. Towards an attention-based view of the firm. Strategic Management Journal, 18: 187-206.

Ouchi, W. G. 1980. Markets, bureaucracies, and clans. Administrative Science Quarterly, 25: 129-141.

Pelled, L. H., \& Adler, P. S. 1994. Antecedents of intergroup conflict in multifunctional product development teams: A conceptual model. IEEE Transactions on Engineering Management, 40: 21-28.

Pohl, R. F. (Ed.). 2004. Cognitive illusions: $A$ handbook on fallacies and biases in thinking, judgment and memory. Hove, UK: Psychology Press.

Rizzo, J. R., House, R. J., \& Lirtzman, S. I. 1970. Role conflict and ambiguity in complex organizations. Administrative Science Quarterly, 15: 150-163.

Robbins, J. M., \& Krueger, J. I. 2005. Social projection to ingroups and outgroups: A review and meta-analysis. Personality and Social Psychology Review, 9: 32-47.

Ross, M., \& Sicoly, F. 1979. Egocentric biases in availability and attribution. Journal of Personality and Social Psychology, 37: 322-336.

Schütz, P., \& Bloch, B. 2006. The "silo-virus": Diagnosing and curing departmental groupthink. Team Performance Management, 12: 31-43.

Shiffrin, R. M., \& Schneider, W. 1977. Controlled and automatic human information processing: Perceptual learning, automatic attending, and a general theory. Psychological Review, 84: 127-190.

Simon, H. A. 1947. Administrative behavior. New York: Macmillan.

Simon, H. A. 1957. Models of man. New York: Wiley. 
Simon, H. A. 1990. Invariants of human behavior. Annual Review of Psychology, 41: 1-19.

Simon, H. A. 1997. An empirically based microeconomics. Cambridge: Cambridge University Press.

Suddaby, R. 2010. Construct clarity and theory development. Academy of Management Review, 35: 346-357.

Svenson, O. 1981. Are we all less risky and more skillful than our fellow drivers? Acta Psychologica, 47: 143-148.

Tajfel, H., Billing, M., Bundy, R., \& Flament, C. 1971. Social categorization and intergroup behaviour. European Journal of Social Psychology, 1: 149-177.

Tate, D. 2010. Turf war at the New York Times: Who will control the iPad? Business Insider, February 16: http://www. businessinsider.com/turf-war-at-the-new-york-times-willcontrol-the-ipad-2010-2.

Taylor, D. M., \& Doria, J. R. 1981. Self-serving and group-serving bias in attribution. Journal of Social Psychology, 113: 201-211.

Thompson, L., \& Loewenstein, G. 1992. Egocentric interpretations of fairness and interpersonal conflict. Organizational Behavior and Human Decision Processes, 5l: 176-197.

Turner, J. C. 1982. Towards a cognitive redefinition of the social group. In H. Tajfel (Ed.), Social identity and intergroup relations: 15-40. Cambridge: Cambridge University Press.

Turner, J. C., Hogg, M. A., Oakes, P. J., Reicher, S. D., \& Wetherell, M. S. 1987. Rediscovering the social group: $A$ selfcategorization theory. Cambridge, MA: Basil Blackwell.

Tversky, A., \& Kahneman, D. 1974. Judgment under uncertainty: Heuristics and biases. Science, 185: 1124-1131.

Vancil, R. F. 1978. Decentralization: Managerial ambiguity by design. Homewood, IL: Dow Jones-Irwin.

Wason, P. C. 1960. On the failure to eliminate hypotheses in a conceptual task. Quarterly Journal of Experimental Psychology, 12: 129-140.

Weber, L., \& Mayer, K. J. 2014. Transaction cost economics and the cognitive perspective: Untangling the impact of informational and interpretive uncertainty on governance choice. Academy of Management Review, 39: 344-363.

Weigelt, C., \& Miller, D. 2013. Implications of internal organization structure for firm boundaries. Strategic Management Journal, 34: 1411-1434.

Whitford, A. B. 2006. Unitary, divisional, and matrix forms as political governance systems. Journal of Management Governance, 10: 435-454.

Wilder, D. A. 1981. Perceiving persons as a group: Categorization and ingroup relations. In D. L. Hamilton (Ed.), Cognitive processes in stereotyping and intergroup behavior: 213-257. Hillsdale, NJ: Lawrence Erlbaum Associates.

Williamson, O. E. 1975. Markets and hierarchies. New York: Free Press.

Williamson, O. E. 1985. The economic institutions of capitalism. New York: Free Press.

Williamson, O. E. 1991. Comparative economic organization: The analysis of discrete structural alternatives. Administrative Science Quarterly, 36: 269-296.

Williamson, O. E. 1996. The mechanisms of governance. Oxford: Oxford University Press.

Williamson, O. E. 1998. Transaction cost economics: How it works; where it is headed. De Economist, 146(1): 23-58.

Williamson, O. E. 1999. Strategy research: Governance and competence perspectives. Strategic Management Journal, 20: 1087-1108.

Williamson, O. E. 2000. The new institutional economics: Taking stock, looking ahead. Journal of Economic Literature, 38: 595-613.

Winkler, R. L., \& Murphy, A. H. 1973. Experiments in the laboratory and the real world. Organizational Behavior and Human Performance, 10: 252-270.

Zajonc, R. B. 1968. Attitudinal effects of mere exposures. Journal of Personality and Social Psychology, 9: 1-27.

Zenger, T. R., Lazzarini, S. G., \& Poppo, L. 2002. Informal and formal organization in new institutional economics. Advances in Strategic Management, 19: 277-305.

Nicolai J. Foss (Njf.smg@cbs.dk) is professor of strategy and organization at the Copenhagen Business School (CBS), department head, Department of Strategic Management and Globalization at CBS, and professor of knowledge-based value creation at the Norwegian School of Economics. He received his Ph.D. from CBS. His interests lie in the theoretical and empirical aspects of microfoundations for strategic management theory and in the intersection of organizational economics and strategic management.

Libby Weber (lweber@uci.edu) is an assistant professor of strategy in the Paul Merage School of Business at the University of California, Irvine. She received her Ph.D. in business administration from the Marshall School of Business, University of Southern California. She studies the microfoundations of organizational economic theories by examining how psychological factors shape behavior, emotions, and cognition in exchanges and impact governance decisions and capability development. 
Copyright of Academy of Management Review is the property of Academy of Management and its content may not be copied or emailed to multiple sites or posted to a listserv without the copyright holder's express written permission. However, users may print, download, or email articles for individual use. 